\title{
内湾域の底質輸送パラメータ推定を目指した オイラー・ラグランジュ計測手法の検討
}

Eulerian-Lagrangian Measurements for Estimating the Sediment Transport Parameters in Estuary

\author{
西 敬浩 ${ }^{1} \cdot$ Charles Lemckert ${ }^{2} \cdot$ 山田文彦 ${ }^{3}$
}

Takahiro Nishi, Charles Lemckert, Fumihiko YAMADA

\begin{abstract}
The novel instrument based on a Lagrangian Acoustic drogue (LAD) has developed for estimating the sediment transport parameters in the estuary. This instrument consists of GPS, ADCP and Nephiometer with Lagrangian drogue. The field experiments using LAD was conducted in Brisbane River, Australia on Dec. 7, 2006. Time-space distributions of the turbidity, horizontal current velocity and direction were obtained. The settling velocity is estimated by analyzing the temporal and spatial changes of the turbidity contour lines. The linear correlation was found to be existed between suspended sediment concentrations (SSC) and settling velocity. An Approximated equation using the method of least means squares agrees well with the results by Van Leussen (1999).
\end{abstract}

\section{1.はじめに}

浅海域での底質輸送や地形変化予測の数值モデルにお いて, 沈降速度や巻き上げ係数などの底質輸送パラメー 夕を推定することは，砂質土のみならず粘性土において も非常に重要である.しかしながら，これらのパラメー 夕を決定する上で重要な浮遊物質の大きさや密度は，潮 汐, 波浪, 河川流入, Suspended Sediment Concentration (SSC), 塩分, 温度, 化学的要因などの影響を受 け，複䧱な環境要因によって支配されている（Voulgaris ・Meyers，2004）。これらの複雑な環境を実験公で再 現するのは，非常に困難であるため（Sternberg ら， 1999), 底質輸送パラメータの推定にあたっては, 対象 とする現地においてこれら環境要因データの取得が不可 欠である。

内湾などの現地において, 沈降速度を観測する手法と して，これまでオーウェンチューブが使われてきた．し かし, Dyer ら (1996) は, この観測機器を使う場合, 浮遊物質を採取する際に, フロックを破壊してしまい, 沈降速度を精度良く推定できないことを指摘している. そこで，オーウェンチューブに代わる観測機器として, OBSなどの光学式計測器 (Fugate - Friedrichs, 2002), 回折作用を利用したLISST-100（Gartnerら，2001）, 音波を使った Acoustic Doppler Current Profiler (ADCP) (Holdaway 5，1999; Hill ら，2003) が開発 され，様々な研究で現地観測に使われてきた。しかしな がら，これらの観测機器を使った観測手法は, 主に固定

\footnotetext{
1 学生会員熊本大学大学院自然科学研究科環境土木工 学専攻

$2 \quad \mathrm{Ph} . \mathrm{D} \quad$ グリフィス大学准教授

3 正 会 員 博(工) 熊本大学准教授大学院自然科学研究科社会 環境工学専攻
}

点観測によるオイラー計測手法であり, 現地で計測され た濁度の上昇が局所的な底質の巻き上げによるものか, それとも，流れに伴って移流してきたものか判別が困難 である (Mikkelsen ら，2006). そのため，底質輸送パ ラメータを精度良く推定するためには，ラグランジュ計 测手法との併用が必要である.

ラグランジュ計測手法として，Drifter または Drogue (ブイの一種) を使った現地観測が，主に外洋において 行われてきた（Niller ら，1995；Righi・Strub, 2001). Johnson·Pattiaratchi（2004）は浅海域である磯浜帯に おいて，GPS を搭載した Drifterによる海浜流の現地観 測を行った。また, Schacht· Lemckert（2005）は, Lagrangian Acoustic Drogue (LAD) を開発し, 内湾 に扮ける浮遊物質の輸送特性の現地観測を行った. $\mathrm{LAD}$ は， 4 つのベーンを有したフロート式ブイに DGPS · ADCP · CTD センサーを搭載したものである. これは, 流れと伴に移動しながら, 流速・濁度・水温・ 塩分の鉛直分布を計測し, それらの輸送フラックスの移 流成分を算定するものである. 本研究は, 潮間帯を含む 内湾浅海域でのオイラー・ラグランジュ計測手法の確立 に向けた初段階として, LADの改良を試み, 現地実験 を行い，その基本性能や沈降速度算定方法を検討した.

\section{2. 観測機器の概要}

本研究では, ラグランジュ計測手法を確立するための 初段階として, Schacht· Lemckert（2005）のフロート 式ブイを参考に, 機器の開発を行った。この観測機器に は，ブイの軌跡を計測するための GPS，浮遊物質の流 速・流向を計測するための ADCPを搭載した。さらに, 流速・流向と同時に濁度の鉛直分布を計測するために, 5 台の比濁計をブイの下に吊るした。図-1 は, 改良型 $\mathrm{LAD}$ の全体図を示している。この機器は, ベーンを含 


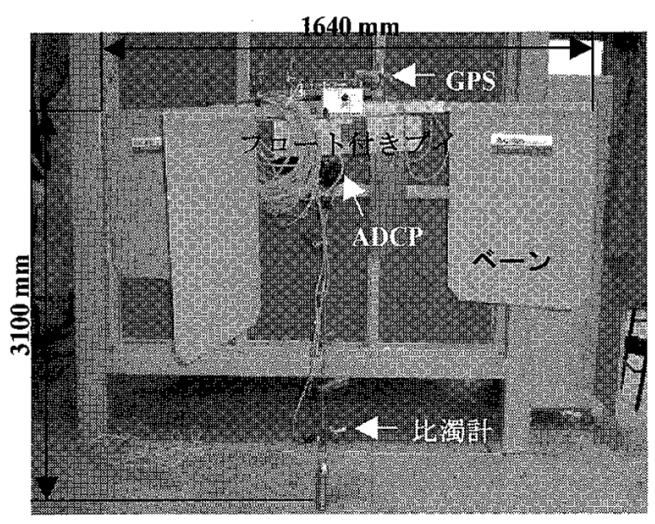

図-1 改良板 LAD

んだ全体の水平方向の長さは約 $1.64 \mathrm{~m}$ であり，鉛直方 向は比濁計を吊るしたワイヤーが約 $3 \mathrm{~m}$ ，フロートを含 めると全体で約 $3.1 \mathrm{~m}$ であった．また，全体の重量は 約 $20 \mathrm{~kg}$ であった.

また，浅海域でも使用可能にするために，既存の $\mathrm{LAD}$ を小型・軽量化する改良を行った，具体的には， ADCP と GPS は小型軽量器である Aquadopp Current Profiler (Nortek) とGPS 76 (GARMIN) に変更した. また，比濁計も小型軽量器である ANALITE 190 (McVAN Instruments) を使用し，さらに軽量化を図 るために, 記憶媒体は比濁計から分離し, 各比濁計とリ ールを使って接続し, 記憶媒体はフロートの上に, バッ テリーと共に搭載した．さらに，記憶媒体とバッテリー については，防水機能を有した箱に収納し，設置した。

GPS については防水バックの使用が不可欠であるの でそれによる位置精度の変化について検討し, 誤差が小 さい防水バックを選択した．防水バックとしては，カバ 一厚が異なる. 3 種類, (1) WATERPROOF GEAR (WXtex), (2) WATERTIGHT BAG SYSTEMS (blackWOLF), (3) PELICAN1060 Micro Case Series (PELICAN) について，位置情報の精度の検証を行った，検 証方法としては，15 秒間隔で 10 分間，固定点に GPS を設置し，それぞれの防水バックに収納した状態で得ら れた緯度・経度について比較した. 固定点の座標は, 南 緯 27 度 57 分 3.5 秒, 東経 153 度 22 分 17.5 秒であった。 図-2 は, 計測された緯度の誤差の時系列を示している。 図より,WATERPROOF GEAR(WXtex)による計測誤 差は，0.09 秒であり，距離に換算すると約 $2.8 \mathrm{~m}$ であ る. 同様に, WATERTIGHT BAG SYSTEMS (blackWOLF) は, 0.02 秒 (約 $1.2 \mathrm{~m}$ ), PELICAN1060 Micro Case Series (PELICAN) は, -0.06 秒(約 $3.7 \mathrm{~m}$ ) であっ た。また，図-3は，計測された緯度の誤差の時系列を 示している．緯度も経度と同様に誤差を求めると， WATERPROOF GEAR(Wxtex)については， -0.43 秒

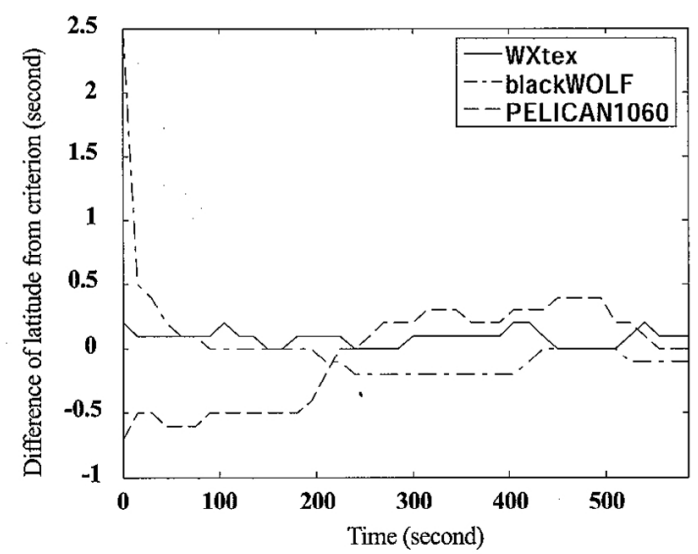

図-2 経度にお拈る固定点の座標功の誤差

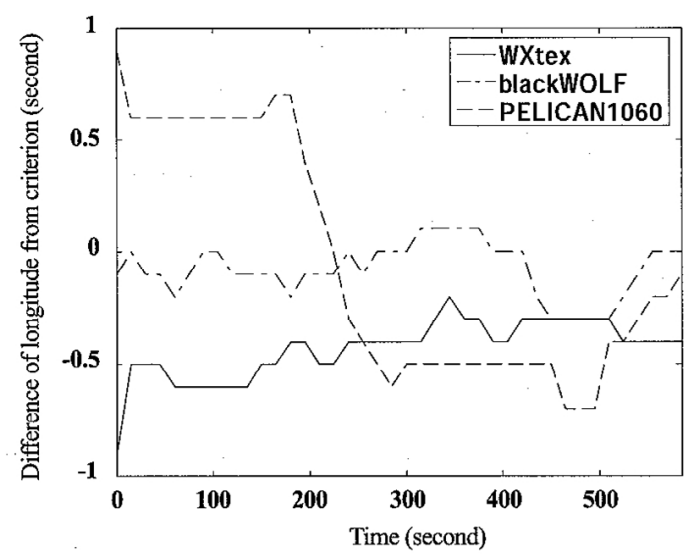

図-3＼cjkstart緯度における固定点の座標からの誤差

(約 $26.6 \mathrm{~m}$ ), WATERTIGHT BAG SYSTEMS (black WOLF) は, -0.08 秒 (約 $4.9 \mathrm{~m}$ ), PELICAN1060 Micro Case Series(PELICAN) は， -0.05 秒(約 $3 \mathrm{~m}$ ) であっ た.

ここで，今回使用する GPS の精度は $\pm 15 \mathrm{~m}$ である ので，防水バックによる影響は比較的小さいと考えられ るが，より位置精度への影響を抑えるために， WATERTIGHT BAG SYSTEMS (blackWOLF) を採 用した。

\section{3. 現地実 験}

\section{（1）実験対象地}

現地実験は，オーストラリアのクイーンズランド州を 流れるブリスベン川（図-4）で行った. ブリスベン川の 流量面積は $13560 \mathrm{~km}^{2}$ で，実験対象地の水深は，最大で 約 $18 \mathrm{~m}$ であった（Eyre ら，1998）。潮位は大潮時に平 均海面から $0.2 \sim 1.9 \mathrm{~m}$ ，小潮時に $0.5 \sim 1.4 \mathrm{~m}$ と変化 する．今回，実験を行った 12 月 7 日は大潮で，実験期 間中の潮位は，水圧計を川岸に設置して計測した。観測 


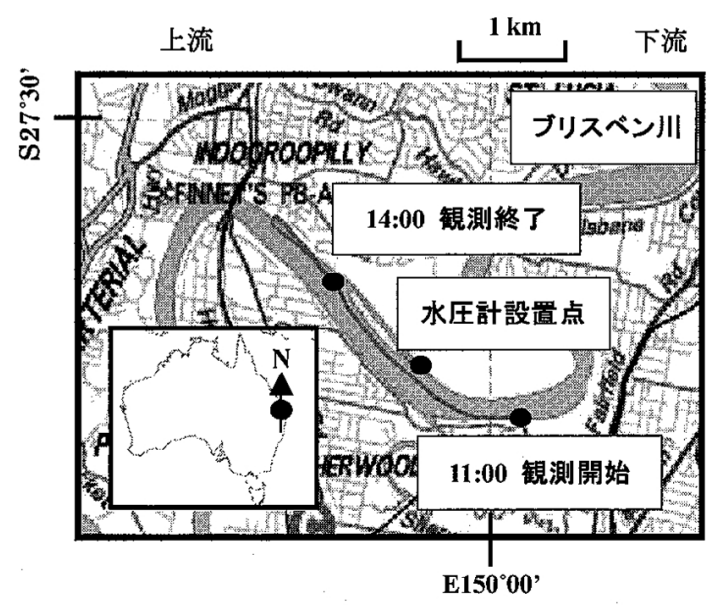

図-4 実験対象地と GPS による改良板 LAD の軌跡

結果より，潮位は河口から実験対象地までの約 $20 \mathrm{~km}$ を約 1 時間半で移動することが確認できた。

\section{（2）実 験 概 要}

実験は，2006 年 12 月 7 日の上げ潮〜満潮 $(12: 30)$ 〜下げ潮の約 3 時間で行った.この日の気象条件は，晴 れで，観測期間中の最大風速は，観測場所に近いブリス ベンで $4.7 \mathrm{~m} / \mathrm{s}$ であった．観測中は，船を用いて改良 型 LAD から $10 \mathrm{~m}$ 程度離れた場所で, 約 15 分ごとに電 気伝導度・水温・塩分の鉛直分布を CTD センサーによ り計測した。 また，キャリブレーションのために，水面 に最も近い比濁計の設置水深である $0.55 \mathrm{~m}$ 付近で採水 サンプリングを行った.さらに，潮位の時系列を計測す るために，水圧計の XR-420 TG (Richard Brancker Research Ltd）を計測間隔 1 分とし，観測期間中，川岸 に設置した(図-4).

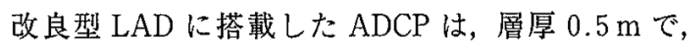
30 層に設定し，1 分ごとに流速·流向を計測した。 また， 比濁計は，鉛直に約 $0.55 \mathrm{~m}$ 間隔で 5 個設置し，5分間 隔で濁度の鉛直分布を計測した. GPSは，防水ケース に収納し, 精度を向上させるために, 約 $45^{\circ}$ 傾けて改良 LAD の上端に設置し，10秒問隔でその軌跡を記録した.

\section{4. 観測 結果}

実測した GPS の軌跡を図-4 に示す。この図から，改 良型 LAD が，最初に上げ潮によって，上流方向に移動 し，下げ潮に変わると，下流方向へと，潮汐と共に向き を変えることが確認できる．また，この時の総移動距離 は $3.93 \mathrm{~km}$ であった。本研究では，息潮時刻の定義を， Schacht・Lemckert（2005）と同様，GPS の位置情報 から算出されるブイの移動速度が最小となる時刻と定義 したため, 秝潮時刻は $12: 57$ であった。水圧計から得ら れた潮位より，満潮時刻は，12:30であったので，約 30

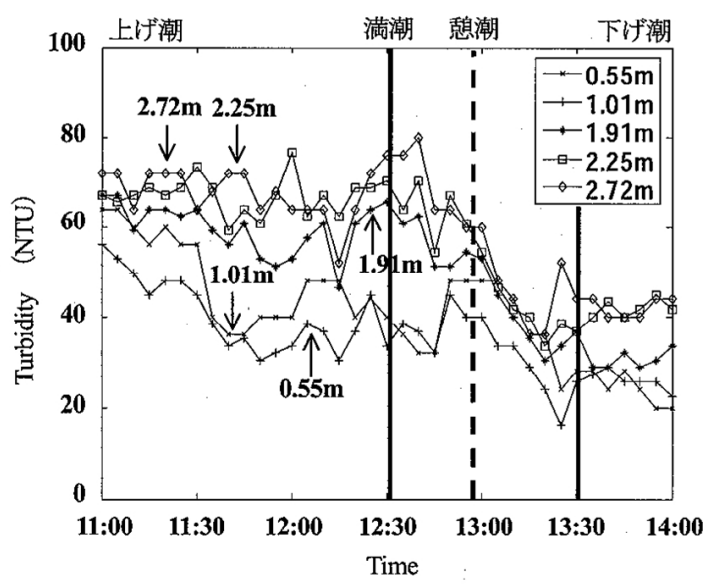

図-5 濁度の時系列（実測值）

分の時間差が生じている。また, CTDから得られた電 気伝導度・塩分・水温より，実験期間中に顕著な成層化 が生じていないことを確認している.

図-5 は，5台の比濁計で計測した濁度 (単位：NTU) の時系列を示している、この中で，凡例は水面から各比 濁計までの鉛直距離（設置水深）を示している. 図より， 上げ潮から満潮にかけて, 水面から $1.01 \mathrm{~m}$ までの表層 付近の濁度は, 約 $60 \mathrm{NTU}$ から $40 \mathrm{NTU}$ と, 時間の経 過と共に減少している。一方, $1.91 \mathrm{~m}$ 以深の濁度は, それぞれ, 約 $70 \mathrm{NTU}$ 付近で, ほほ一定の值を保った ままである，その後，全観測深度で濁度の急激な低下が 見られる。これは, 唕潮時刻の約 30 分前である満潮時 刻付近から，憩潮時刻の約 30 分後に当たる $13: 30$ まで の約 1 時間の間で生じており，この低下傾向は，設置水 深が深いほど顕著であることが確認できる。これは，潮 汐による水平方向流速の減少により, 浮遊物質の沈降が 生じたものと考えられる。 その後, 潮汐による水平方向 流速の増加に伴って，13:30 頃から再び，下層の濁度が 徐々に上昇しており，浮遊物質の（再）巻き上げを捉え たものと推察される。

次に, 比濁計で計測された濁度と, ADCP で計測さ れた水平方向流速・流向との関係を検討した。これらの 実測值の時空間変動を図-6に示す. 図中の流速は, GPSによる表層流速との相対速度であり，同一平面内 で北向き流速を $u(+)$, 東向き流速を $v(+)$ とし, 式 （1）による合成流速 $V$ として表示した.

$$
V=\sqrt{u^{2}+v^{2}}
$$

なお，流向は真北から時計回りの角度を表す，流速・流 向については，水深 $15.4 \mathrm{~m}$ まで計測を行ったが, 此濁 計で計測された水深 $3 \mathrm{~m}$ までの時空間分布と比較する ために，ここでは, 水深 $6 \mathrm{~m}$ までの実測值のみを示し 


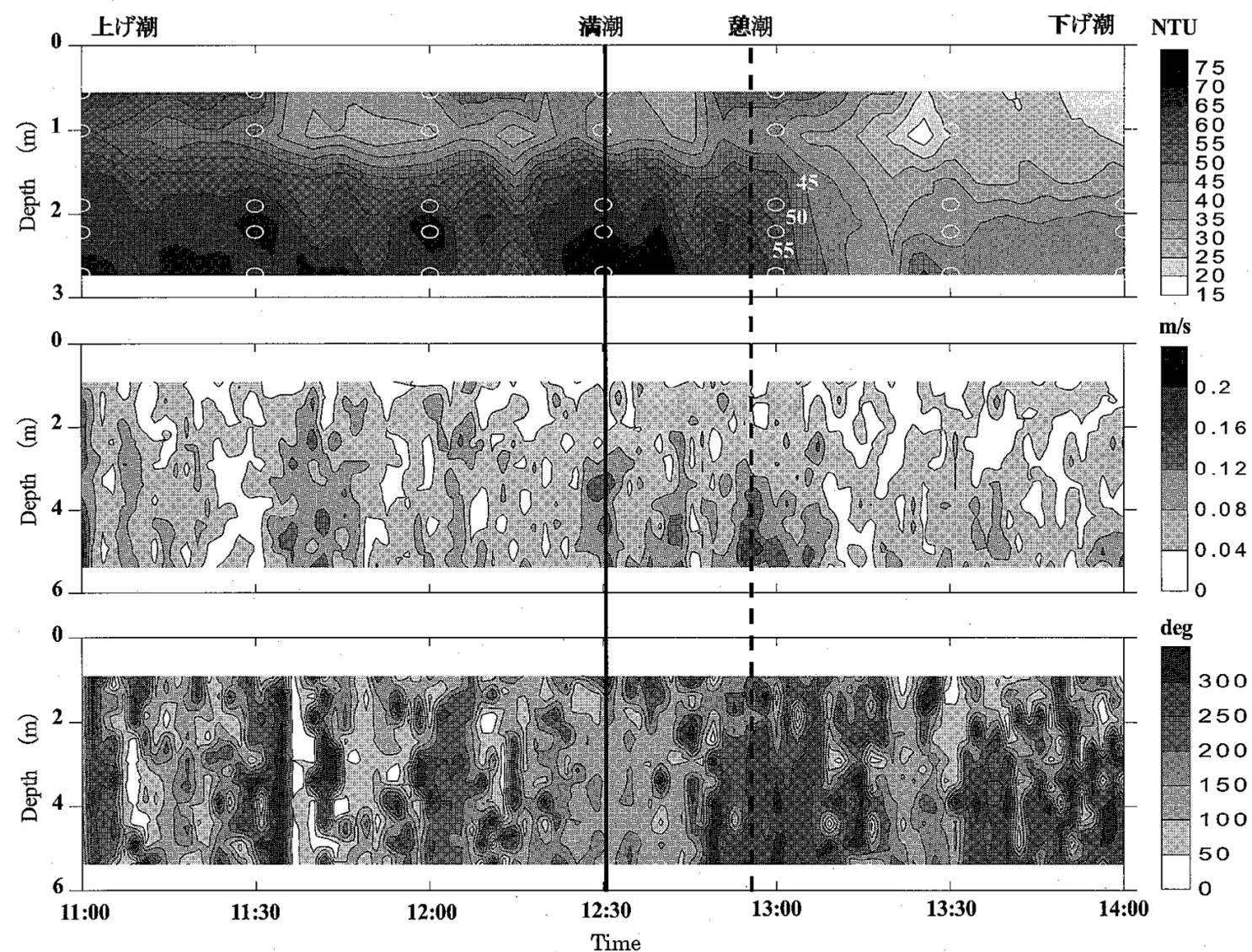

図-6 改良版 LAD による（a）濁度・（b）流速・（c）流向の時空間分布

ている.

図-6 (a) は濁度の時空問分布を示しており，図中の白 円は，各濁度計の設置水深を 30 分毎に示したものであ る. 濁度の時架間分布は, 5 点での実測值を時空間方向 に補間する事で算出した，図より，各比溞計の溞度の時 系列（図-5）が示す傾向と同㥞に，観測開始から数潮時 刻前まで濁度が減少し，颕潮時刻後には，特に底面付近 で濁度が再び増加していることが確認できる。また， 図-6(b)が示す水平方向流速の実測值からは，悡潮時刻 前では, 水深が約 $4 \mathrm{~m}$ の地点で, 最大で $0.16 \mathrm{~m} / \mathrm{s}$ 以上 の流速が観測されているが，賏潮時刻後には，全水深で， 最大で $0.08 \mathrm{~m} / \mathrm{s}$ 程度の流速しか観測されておらず，潮 汐の変化と伴に流速が減少していることが碓認できる. さらに，図-6(c)が示す流向の実測值からは，㮩潮時刻 前に $150^{\circ} \sim 200^{\circ}$ だった流向が，䅣潮時刻後には， $300^{\circ}$ 〜360。変化していることが確認できる.このことか らも, 潮汐と伴に内部の流速も方向を変えていることが 確認できた。これらの結果は，本研究で開発した改良型 LAD は, 潮汐変動に伴う浮遊物質の流動場特性を, ラ グランジュ場に㧍いて計測可能であることを示唆してい
る。また，潮汐が唕潮時刻に差しかかると，水平流速が 減少し，それと同時に浮遊物質が沈降し，さらに敀潮時 刻を過き，再び水平流速が卓越してくると，浮遊物質が 再び巻き上がるという特徵を計測可能であることが確認 された。

\section{5. 沈降速度の検討}

Dyer ら (1996)や Van Leussen (1999)はオーウェンチ ューブなどの機器を使って，内湾に㧍ける現地観測から， 式（2）に示すSSC と沈降速度の関係式を算出した.

$$
W_{b s}=k C^{n}
$$

ここで, $W_{b s}$ は沈降速度 $(\mathrm{mm} / \mathrm{s}), C$ は SSC $(\mathrm{mg} / \mathrm{l})$, $k \cdot n$ は実測值から得られる現地に依存した定数を示し ている. その中で, Van Leussen（1999）は $n$ について は一般的に $0.5 \sim 3.5$ の範囲にあること示している.

本研究でも, 同様に, SSC と沈降速度の関係式を求 めるために，比濁計で計測した濁度（単位：NTU）を， 採水サンプリングによって得られた SSC (mg/l) を使 ってキャリブレーションを行った，その結果，濁度と 


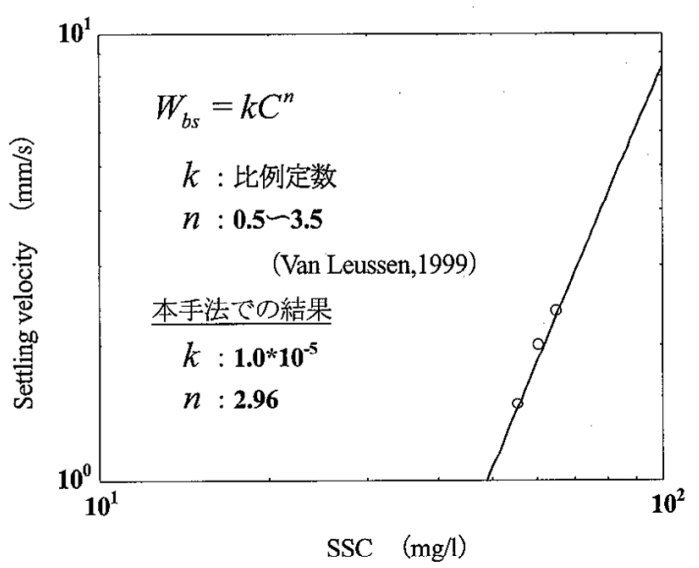

図-7 濁度の時空間分布から算出した沈降速度と近似曲線

SSC の相関は比較的高く（相関係数 0.75）, 両者の関係 式は式（3）で近似できる.

$$
S S C=0.80 N T U+6.41
$$

沈降速度を算定する手法として, Schacht・Lemckert （2005）は濁度の時空間分布を示す等值線を使って算出 する独自の手法を提案している，その手法は，濁度が低 下し始める地点と, 濁度が再び上昇する地点, または, 観測終了地点までを直線近似し，その傾きを沈降速度と 定義するものである. 本研究でも，同様の手法を 45 ・ $50 \cdot 55$ NTU の濁度の等值線（図-6(a)）に適用した。

図-7は，濁度の時空間分布から算出した沈降速度 （図中の○）とその近似曲線を示している. 今回は濁度 が $100 \mathrm{mg} / 1$ 以下の範囲を対象としており，近似式とし ては式（4）が得られた。

$$
W_{b s}=1.0^{*} 10^{-5} C^{2.96}
$$

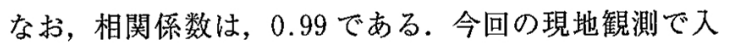
手できた推定值は 3 点と少なかったが, 近似式の指数部 分 $(n=2.96)$ は, Van Leussen (1999) が示した指数 の範囲 $(n=0.5$ ～$n .5)$ にあることが確認できた。

\section{6. とめ}

本研究では, 潮間帯を含む内湾浅海域でのオイラー・ ラグランジュ計測手法の確立に向けた初段階として, LAD の改良を試み, 現地実験を行い，その基本性能な どの検討を行った. 観測結果から, 改良型 LAD は, 潮 汐と共に移動し, 浮遊物質の輸送特性を調べるための濁 度·水平流速・流向を計測できることを確認することが出 来た。また, 実験的ではあるが, 取得した濁度の等值線 から沈降速度を算出することができた. さらに, その近 似式が Van Leussen（1999）が示した指数の範囲（ $n=$
0.5 ～3.5）にあることが確認できた.

しかしながら, 本計測機器やデー夕解析手法に関して は，まだ改良・検討の余地が残されており, さらなる改 良や検証実験を実施し，精度検証を実施する予定である.

\section{参考文 献}

Dyer, K.R., Cornelisse, J., Dearnaley, M.P., Fennessy, M.J., Jones,S.E., Kappenberg, J.,McCave, I.N., Pejrup, M., Puls, W., Leussen, W.V. and Wolfstein. K. (1996):A comparision of in situ techniques for estuarine floc settling velocity measurements, Journal of Sea Research, 36, pp. 15-29.

Eyre, B., Hossain, S. and McKee, L. (1998) : : A suspended sediment budget for the modified subtropical Brisbane River estuary. Australia, Estuarine, Coastal and Shelf Science, 47 , pp. 513-522.

Fugate, D.C. and Friedrichs, C.T. (2002) :Determining concentration and fall velocity of Estuarine particle populations using ADV, OBS and LISST, Continental Shelf Research, 22, pp. $1867-1886$.

Gartner, J.W., Cheng, R.T., Wang, P.F. and Richter, K. (2001) :Laboratory and field of the LISST-100 instrument for suspended particle size determinations, Marine Geology, 175, pp. 199-219.

Hill, D.C., Jones, S.E., and Prrandle, D. (2003) :Derivation of sediment resuspension rates from acoustic backscatter time-series in tidal waters, Continental Shelf Research, 23, pp. $19-40$.

Holdaway, G.P., Thorne, P.D., Flatt, D., Jones, S.E. and Prandle, D. (1999): Comparison between ADCP and transmissometer measurements of suspended sediment concentration, Continental Shelf Science, 61, pp. 539-545.

Johnson, D. and Pattiaratchi, C. (2004) :Application modeling and validation of surfzone drifters, Coastal Engineering, 51, pp. 455-471.

Mikkelsen, O.A., Hill, P.S. and Milligan, T.G.(2006) :Single-grai$\mathrm{n}$. microfloc and macrofloc volume variations observed with a LISST -100 and a digital floc camera, Journal of Sea Research, 55, pp. 87-102.

Niller, P.P., Sybrandy, A.S., Bi, K., Poilain, P.M. and Bitterman, D. (1995): Measurement of the water following capability of holey-sock and TRISTAR drifters, Deep-Sea Resurch I, 42(11/12), pp. 1951-1964.

Righi, D.D. and Strub, P.T.(2001) :The use of simulated drifters to estimate vorticity, Journal of Marine Systems, 29, pp. 125-110.

Schacht, C. and Lemckert, C (2005):A new Lagrangian-based Acoustic Drogue (LAD) for mornitoring flow dynamics in an estuary: a quantification of its water tracking ability, Flow Measurement and Instrumentation(投稿中)

Sternberg, R.W., Berhane, I. and Ogston, A.S (1999):Measurement of size and settling velocity of suspended aggregates on the northern California continental shelf, Marine Geology, 154, pp. 43-53.

Van Leussen, W (1999): The variability of settling velocities of suspended fine-grained sediment in the Ems estuary, Journal of Sea Research, 41, pp. 109-118.

Voulgaris, G. and Meyers, S.T (2004):Temporal variability of hydrodynamics, sediment concentration and sediment settling velocity in a tidal creek, Continental Shelf Research, 24, pp. 1659-1683. 